\title{
Kimya Öğretmeni Adaylarının Fizikokimya Laboratuvar Deneylerini Öğrenmelerine V-Diyagramının Etkisi ve V-Diyagramı ile İlgili Görüşleri1 ${ }^{1}$
}

\author{
DOI: 10.26466/opus.538372 \\ * \\ Emine Güler Akgemci* - Derya Karataş** \\ * Prof. Dr., Necmettin Erbakan Üniversitesi, Ahmet Keleşoğlu Eğitim Fak. Meram/Konya/ Türkiye \\ E-Posta: egakgemci@gmail.com \\ ORCID: 0000-0002-9744-1931 \\ ** Öğretmen, Atatürk Anadolu Lisesi, Selçuklu/Konya/Türkiye \\ E-Posta: derya_karatas@mynet.com \\ ORCID: $0000-0003-4827-9613$ \\ *** Doç. Dr., Necmettin Erbakan Üniversitesi, Ahmet Keleşoğlu Eğitim Fak. Meram/Konya/ Türkiye \\ E-Posta: aderman1977@gmail.com \\ ORCID: $\quad$ 0000-0003-3856-1017
}

\begin{abstract}
Öz
Bu çalı̧̧mada, 3. sınıf kimya öğretmeni adaylarının Fizikokimya Laboratuvarı I dersi deneylerinin raporların V-Diyagramı kullanarak hazırlamalarının Fizikokimya Laboratuvarı I dersi deneylerini öğrenmelerine etkisi araştırılmıştır. Bu çalışmada deney öncesi desenlerden durağan grup karşılaştırması (denkleştirilmemiş gruplarda sontest) deseni kullanılmıştır Fizikokimya Laboratuarı I dersini alan 56 öğrenci rastgele atamayla deney grubu ve kontrol grubu olarak iki gruba ayrılmıştır. Deney grubundaki öğrenciler deney raporların $V$ Diyagramı kullanarak hazırlarken, kontrol grubundaki öğrenciler deney raporlarını alşageldikleri, klasik biçimde hazırlamışlardır. Elde edilen nicel veriler betimsel istatistik teknikleri ile analiz edilerek iki öğrenci grubunun başarısı karşılaştıılmıştır. Nitel verilerin analizinde içerik analizi tekniğgi kullanılmıştır. Bu çalışmada elde edilen sonuçlara göre $V$ Diyagramının öğrencilerin fizikokimya laboratuvar deneylerini öğrenme başarısını arttırdığın söyleyebiliriz. Bu çalışmada elde edilen bulgulara dayah olarak laboratuvar çalışmaların daha verimli ve anlamlı kılmak amacıyla, geleneksel öğretim yaklaşımlarının esas alındığı laboratuvar uygulamalarının dışına çıkılarak öğrancinin öğrenmede daha çok sorumluluk aldığı ve aktif olduğu çă̆daş öğretim yaklaşımlarının esas alındığı laboratuvar uygulamaları kullamılmalıdır. Bu çalışmada elde edilen bulgulara dayalı olarak V diyagramlarının laboratuvar çalışmaların daha etkin ve anlamlı kılma ve öğrencilerin öğrenmelerine katkıda bulunma potansiyeline sahip olduğunu söyleyebiliriz.
\end{abstract}

Anahtar Kelimeler: Kimya öğretmeni adayı, fizikokimya laboratuvarı, V-diyagramı, öğrenme

\footnotetext{
${ }^{1}$ Bu makale, Derya KARATAŞ tarafından hazırlanan "V-Diyagramının Klasik ve Similasyonlu Fizikokimya Laboratuvar Deneylerini Öğrenme Başarısına Etkisi" isimli yüksek lisans tezinden üretilmiştir.
} 


\title{
Effect of The V-Diagram on The Prospective Chemistry Teachers' Learning of Physical Chemistry Laboratory Experiments and Their Ideas About V-Diagram
}

\begin{abstract}
In the present study, we investigated the effects of the preparing the reports of Physical Chemistry Laboratory I course experiments via $V$-Diagram on the learning of physical chemistry laboratory experiments of 3 rd grade prospective chemistry teachers. In the present study, Static Group Comparison Pattern, one of the pre-experimental design was used. 56 prospective chemistry teachers, who are learning Physicochemistry Laboratory I Course, separated randomly as a an experimental group and control group. While the students in the experimental group prepared the experiment reports using V Diagram, the students in the control group prepared the experiment reports in a traditional way. The quantitative data were analized by using descriptive statistical techniques and the success of the students in both groups were matched. The content analysis technique was used for analyzing the qualitative data. According to the results obtained in this study, we can say that the $V$ diagram increases the students' success in learning the physical chemistry laboratory experiments. Based on the findings obtained in this study, in order to make the laboratory studies more efficient and meaningful, the laboratory practices based on the contemporary teaching approaches in which the student takes more responsibility and active in learning should be used by going beyond the laboratory practices based on traditional teaching approaches. Based on the findings obtained in this study, we can say that $V$ diagrams have the potential to make laboratory studies more effective and meaningful and to contribute to students' learning.
\end{abstract}

Keywords: Prospective chemistry teachers, physical chemistry laboratory, V-diagram, learning, 


\section{Giriş}

Fen bilimlerini diğer bilimlerden ayıran en önemli özellik; öncelikle deneye, gözleme, keşfe önem vererek öğrencide bilimsel süreç becerilerinin gelişmesine (Adadan, 2015; Nakipoğlu, 2015) imkân sağlamasıdır. Bilim ve teknolojinin baş döndürücü bir hızla geliştiği günümüzde fen eğitimi çok farklı teknik ve yöntemlerle gerçekleştirilmektedir. Bu yöntemler içerisinde en etkili olanlardan bir tanesi de laboratuvar yöntemidir (Lawson, 1995). Temel fen bilimlerinde teorik konuların deneyle desteklenmesi konuların anlaşılması açısından son derece önemlidir. Fen eğitiminde laboratuvar uygulamalarının odak noktası niteliğinde önemli bir rolü vardır (Adadan, 2015). Bu nedenle fen öğretiminde laboratuvarların fonksiyonu konusu birçok araştırmacının ilgisini çekmiştir (Adadan, 2015; Hodson, 1990; Hoffstein ve Lunetta, 1982; Tamir, 1977). Laboratuvar çalışması; muhakemeyi ve eleştirel düşünmeyi, bilimi anlamayı, işlem yeteneklerini, el becerilerini etkiler ve öğrencilerin bilgiyi kullanmalarını, genel bir kavramı geliştirmelerini, yeni bir problemi tanımalarını, bir gözlemi açıklamalarını ve karar vermelerini sağlar. Uygun kullanıldığı takdirde laboratuvar çalışmalarının öğrencilerin hem temel bilimsel kavramları ve bilimin doğasıyla ilgili kavramları anlamalarına hem de bilimsel süreç becerilerini (Nakipoğlu, 2015) kazanmalarına imkân tanıyacak potansiyeli olduğu vurgulanmaktadır (Adadan, 2015). Fen bilimleri derslerinde anlamlı öğrenmenin sağlanması ve kalıcı bilgilerin elde edilmesinde laboratuvar çalışmalarının önemli bir yeri vardır. Laboratuvar çalışmalarının amacı, öğrencilerin derslerde gördükleri teorik bilgileri laboratuvar deneyleri ile teyit etmelerine imkân sunarak onların anlamlı ve kalıcı öğrenmelerini gerçekleştirmek ve öğrencilere bilimsel araştırma yeteneği kazandırmaktır (Serin, 2002; Sülün, Evren ve Sülün, 2009). Bu yapılırken de çoğunlukla tümdengelim yaklaşımı kullanılmaktadır. Bu durumda laboratuvar çalışmalarının amacına ulaşması, derslerdeki teorik bilgiler ile deneyler arasında anlamlı ilişkiler kurulmasına ve laboratuvarın aynı zamanda bir öğrenme ortamı haline getirilmesine bağlıdır (Nakiboğlu ve Meriç, 2000). Bununla birlikte laboratuvar çalışmalarının bu amaçları gerçekleştirmedeki etkinliği konusunda bazı yetersizliklerin olduğunu gösteren çalışmalar vardır. Geleneksel laboratuvar çalışmaları, öğrencilerin deneyleri planlama, gözlem 
yapma, ölçme ve sonuç çıkarma gibi bilimsel süreç becerilerini geliştirmede yeterince etkili olmamaktadır (Tamir, 1977; Kyle, Penick ve Shymansky, 1979). Nakhleh (1994), laboratuvarların bir öğrenme ortamı olarak düşünülmesine yönelik yaptığı bir çalışmasında, özellikle yapılandırmacı öğrenme teorisi'nin dayandığı temel nokta olan bilginin öğrencinin zihninde yapılandırılması görüşünü de dikkate alarak, laboratuar ortamında öğrencilerin bilgilerini tam olarak yapılandıramadıklarını belirtmiştir. Bunun nedenini de 'pek çok faktörden etkilenen laboratuar ortamında, öğrencinin bilgiyi zihninde yapılandıramadığ 1 ve bunun öğrenciyi anlamlı öğrenmeden çok ezberci bir öğrenmeye götürdüğ̈̈' şeklinde açıklayarak bu durumun laboratuvarları, sadece öğrencilerin el becerilerini geliştirdikleri bir yer olmaktan öteye götüremediğini belirtmiştir. Laboratuvar çalışmalarıyla ilgili olarak fen eğitimi araştırmalarının bulgularına dayalı olarak ortaya konan bu problemlerin giderilebilmesi ve öğrencilerin laboratuvar çalışmaları yoluile fen derslerindeki konu alanlarında anlamlı ve kalıc bilgi yapıları oluşturabilmeleri için V-diyagramları ve kavram haritaları gibi farklı görsel öğretim materyallerinden yararlanılması gerektiği vurgulamaktadır (Çelikler, Güneş, Güneş ve Şendil, 2008; Nakiboğlu ve Meriç, 2000; Yavuz ve Kıyıc1, 2014)

Öğrencilerin; kimya biliminin temel kavramları, ilkeleri, modelleri, teorileri ve yasaları hakkında bilgi sahibi olmaları, kimya biliminin ve insanlığın ortak mirası olan bilimsel bilginin gelişim sürecini ve doğasını kavramaları, kimya dersinde edindikleri bilgi ve becerileri günlük hayat, sağlık, sanayi ve çevre ile ilgili olayları açıklamada kullanmaları, kimyanın topluma, sosyal hayata, ekonomiye ve teknolojiye katkılarının farkına varmaları ortaöğretim Kimya Dersi Öğretim Programı'nın (MEB, 2018) amaçları arasındadır. Kimya öğretim programında vurgulanan bu amaçlara ulaşılmasında etkin laboratuvar çalışmalarının rolü çok fazladır. Kimyanın bütün dallarının ve fiziğin öğretiminde olduğu gibi fizikokimyanın öğretiminde de laboratuvar uygulamaları ve deneyler önemli yer tutmaktadır. Fizikokimya, kimya ve fizik bilimlerinin kesiştiği alanda yer alan önemli bir kimya dalıdır. Zamanla çok gelişen fizikokimya ana bilim dalı, termodinamik, elektrokimya, kimyasal kinetik, polimer kimyası, çekirdek kimyası, kuantum kimyası, spektroskopi ve istatistik termodinamik gibi alt dallara ayrılmıştır (Sarıkaya, 1993). Fizikokimya dersi 
kapsamında gazlar, termodinamik, maddenin halleri, karışımlar, kimyasal termodinamik, elektrokimya, yüzey kimyası ve koloitler gibi konular kapsamlı bir şekilde işlenmektedir. Fizikokimya alanındaki çalışmalar, mikroskopik ve makroskopik yaklaşımlarla iki farklı yoldan yürütülmektedir. Miktarı, hacmi, basıncı ve sıcaklığı ölçülebilecek kadar büyük olan maddeler, makroskopik yaklaşımla deneysel olarak incelenebilmektedir. Termodinamik, elektrokimya, kimyasal kinetik ve polimer kimyası içindeki incelemeler makroskopiktir. Fiziksel ve kimyasal olaylardaki denge koşulları termodinamik; denge konumuna gelene dek izlenen yollar ve dengeye ulaşma hızı ise kimyasal kinetik içinde incelenir. Atom, elektron, iyon ve molekül gibi çok küçük parçacıklar, mikroskopik yaklaşımla kuramsal olarak incelenmektedir. Kuantum kimyası, spektroskopi ve istatistik termodinamik içindeki incelemeler mikroskopiktir. Moleküler kinetik kuram ile maddelerin makroskopik özellikleri ile mikroskopik özellikleri birbirine bağlanabilmektedir (Sarıkaya, 2003). Fizikokimya dersi ile ilgili olarak gerçekleştirilen laboratuvar çalışmalarında ise yukarıda adı geçen konular kapsamında çeşitli fizikokimya deneyleri seçilerek laboratuvar uygulamaları gerçekleştirilmektedir.

$\mathrm{Bu}$ bilgiler ışığında, bu çalışmamızda geleneksel yaklaşımla gerçekleştirilen fizikokimya deneylerinin raporlarının hazırlanmasında, laboratuvar ortamında edinilen bilgiyi öğrencinin anlamlı, kalıcı ve organize olarak zihninde yapılandırmasına imkân sunan V-Diyagramlarını kullanarak fizikokimya laboratuvar uygulamalarının niteliğini arttırmayı hedefledik.

Bu çalışmada V-Diyagramının Fizikokimya laboratuvarlarında deney raporlarının hazırlanmasında kullanılmasının kimya öğretmeni adaylarının Fizikokimya Laboratuvar deneylerini öğrenmesine olan etkilerine odaklanıldı.

\section{Kuramsal Çerçeve}

\section{Vee Diyagramları ve Fen Öğretimindeki İşlevi}

V-diyagramı Gowin ve Novak'ın (1984), öğrencilerin bilgiyi daha iyi anlayıp yapılandırması amacı ile 70'li yıllardaki çalışmaları sırasında geliştirdiği V-şeklinde bir diyagramdır ve Vee heuristiği, Vee haritası ve 
V-Diyagramı olarak da isimlendirilmektedir. Gowin ve Novak tarafından geliştirilen bu araç, hem bilgi birimleri arasında ilişki kurarak anlamlı öğrenmeyi sağlayan bir anlamlandırma stratejisi, hem de öğrenilecek bilgilerin yeniden düzenlenip, yapılandırılarak öğrenilmesini sağlayan bir örgütleme stratejisidir. V-Diyagramı anlamlı öğrenmeyi gerçekleştiren metakognitif araçlardan biridir. Metakognitif stratejiler, öğrencilerin daha güçlü ve bütüncül bilişsel yapılar kurmalarına izin veren öğrenme stratejileridir. Bu araçlar öğrencilerin öğrenmenin nasıl meydana geldiğini ve bilginin nasıl oluştuğunu anlamalarına da yardımcı olur. Passmore (1998), metakognitif stratejileri kullanarak öğrencilerin çalıştıkları bilginin kavramsal, ilişkisel ve hiyerarşik doğasını inceledikleri için anlamlı bir şekilde öğrendiklerini belirtmektedir.

$\mathrm{Bu}$ diyagram öğrencilerin teorik bilgi ile laboratuvar çalışmaları arasında ilişki kurmalarını sağlayarak, laboratuvar raporlarının daha anlaşılabilir ve yararlı hale getirilmesine imkân tanır (Gowin ve Novak, 1984; Novak, 1998).

Laboratuvar çalışmalarında V-diyagramını kullanmanın en büyük yararı, öğrencilerin sahip oldukları teorik bilgiyle laboratuvardaki gözlemleri arasında ilişki kurmalarını sağlayarak, ders ve laboratuvar çalışması arasındaki kopuklukların giderilmesidir. Öğrenciler çoğu zaman laboratuvarda yaptıkları deneylerde, deneyin kayıt ve sonuçları ile ilgilenirken, deneyin aslında öğrenciye kazandırmak istediği kavramsalbilgiye ulaşamamaktadırlar. V-diyagramını kullanarak, öğrenciler elde ettikleri kayıtlardan yola çıkarak, veri dönüşümlerini oluştururlar ve buradan da deneyin kazandırmak istediği deneysel ve bilgisel yorumlara ulaşırlar (Nakiboğlu, Benlikaya ve Karakoç, 2001; 2002).

Roth (1990) çalışmasında kavram haritası ve V Diyagramı kullandı fen laboratuvarı derslerinde öğrencilerin bu teknikleri kullanmayan öğrencilere göre daha başarılı olduğunu, öğrencilerde laboratuvar çalışmalarına karşı isteğin, bireysel öğrenmenin ve sınıf üretkenliğinin arttı̆̆ını tespit etmiştir. Gurley ve Dilger (1992), öğrencilerin V-Diyagramlarıyla teorik derste öğrenilen bilgiler ışığında laboratuvar çalışmalarının amacını daha iyi görebildiklerini ve bilimsel bilgilerin kesinlik gösteremediğini öğrendiklerini belirtmiştir.

Esiobu ve Soyibo (1995), ekoloji ve genetik konularının öğretiminde kavram haritası ve V-diyagramlarını kullanıldıkları çalışmalarında, 
kavram haritası ve V-diyagramının kullanıldığı öğrenci grubunun kontrol grubuna göre daha başarılı olduğunu tespit etmiş̧lerdir.

Roegrih, Luft ve Edward (2001), öğrencilerin V-Diyagramı oluştururken hem bilimsel bilginin nasıl geliştirildiğini gördükleri hem de birbirleriyle ve öğretmenle iletişim içerisinde bilgileri yapılandırma sürecinde sosyal becerilerini geliştirdiklerini belirtmişlerdir. Nakiboğlu, Benlikaya ve Kalın (2002); V-Diyagramını kimyasal kinetik ile ilgili yanlış kavramların belirlenmesinde kullanmışlardır. V-Diyagramılla konu ile ilgili ön bilgilerdeki eksikliklerden, yanlış kavramalardan ve veri yorumlamadaki hatalardan kaynaklanabilecek yanlış kavramların belirlenebileceğini sonucuna varmışlardır. Ayvacı ve İpek Akbulut (2012) çalışmalarında; V-diyagramının öğrencilerin psikomotor becerilerini geliştirdiğini, bilişsel alanda kavramsal öğrenmeye katkı sağladığını ve öğrencilerin alma, karşılık verme gibi alt düzeyde de olsa bazı duyuşsal özelliklerini etkilediğini tespit etmişlerdir.

Yavuz ve Kıyıcı (2014) fen ve teknoloji laboratuar uygulamaları dersinde kavram haritası ve V-diyagramı kullanımının sınıf öğretmenliği adaylarının ders başarıları ve eleştirel düşünme eğilimlerine etkisini inceledikleri çalışmalarında, laboratuvarda eğitim öğretim faaliyetleri içerisinde V-diyagramı ve kavram haritası kullanımının öğrencilerin başarı ve eleştirel düşünme eğilimlerini olumlu yönde etkilediğini tespit etmişlerdir.

\section{Yöntem}

\section{Araştırma Modeli}

$\mathrm{Bu}$ çalışmada deney öncesi desenlerden durağan grup karşılaştırması (denkleştirilmemiş gruplarda sontest) deseni kullanılmıştır (Creswell, 2016, s. 172).

\section{Çalışma Grubu}

Bu çalışma, 2006 - 2007 akademik yılında İç Anadolu Bölgesi'nde bulunan bir devlet üniversitesinin Eğitim Fakültesi Kimya Öğretmenliği Programının 3. ve 4. sinıflarında okuyan toplam 109 öğrenci ile yürütülmüştür. 


\section{Diyagramı Uygulaması}

Çalışma iki kısımdan oluşmaktadır. İlk kısımda, 2006- 2007 akademik yılı güz döneminde Selçuk Üniversitesi Eğitim Fakültesi Kimya Öğretmenliği Bölümü Fizikokimya Laboratuvarı- II dersini alan 53 dördüncü sinıf öğrencisiyle bir pilot çalışma yapılmıştır. Bu çalışmada öğrencilere V Diyagramları anlatılarak bir grubun deney raporlarını bu şekilde hazırlamaları istenmiştir. Bu aşamada öğrencilerin fizikokimya deney raporlarını Vdiyagramı kullanarak hazırlamaya yönelik tutum ve yaklaşımları gözlemlenmiş, uygulamanın problemli ve eksik noktaları tespit edilerek asıl uygulamada bu hususların iyileştirilmesine özen gösterilmiştir.

Asıl uygulamanın yapıldığı çalışmanın ikinci kısmı, 2006 - 2007 akademik yılı bahar döneminde Fizikokimya Laboratuvarı-I dersini alan 56 üçüncü sınıf kimya öğretmeni adayıyla gerçekleştirilmiştir. Sınıf iki gruba ayrılarak, hangi grubun deney grubu hangi grubun kontrol grubu olacağına rasgele karar verilmiştir.

Tablo 1. Fizikokimya laboratuvarında çalışılan deneyler

\begin{tabular}{ll}
\hline Deney No & Deney Adı \\
\hline $1-$ & Asedik asidin aktif karbon üzerindeki adsorpsiyonunun incelenmesi \\
\hline $2-$ & İletkenlik metodu ile çözünürlük tayini \\
\hline $3-$ & İletkenlik titrasyonu \\
\hline $4-$ & İdeal gaz kanunları, Boyle Kanunu'nun uygulanması \\
\hline $5-$ & $\begin{array}{l}\text { Çözeltilerde yüzey gerilimi ve yüzey geriliminin konsantrasyonla de- } \\
\text { ğişimi }\end{array}$ \\
\hline $6-$ & $\begin{array}{l}\text { Oswald viskozimetresi ile viskozite tayini ve viskozitenin sıcaklıkla } \\
\text { değisisiminin incelenmesi }\end{array}$ \\
\hline $7-$ & Nötralleşme isısının hesaplanması \\
\hline $8-$ & Tuzlu suyun elektrolizi, faraday sabiti ve avagadro sayısının tayini \\
\hline $9-$ & Sollerin hazırlanması \\
\hline
\end{tabular}

Deney grubundaki öğrencilere ilk olarak V-Diyagramları tanıtılmış, çeşitli V-Diyagramı örnekleri üzerinde çalışılıp, tartışılarak V-Diyagramı kavratılmaya çalışılmıştır. Önceki yıllarda yaptıkları bir deneyle ilgili Vdiyagramı hazırlamaları istenmiştir. Bu öğrencilerden dönem boyunca deney raporlarını V-Diyagramı şeklinde hazırlamaları, kontrol grubu 
öğrencilerinden ise dönem boyunca deney raporlarını alışageldikleri, klasik deney raporu şeklinde hazırlamaları istenmiştir.

Dönem sonunda deney grubu öğrencilerinin laboratuvara yönelik tutumlarını ve V Diyagramı ile ilgili düşüncelerini belirlemek amacıyla 25 soruluk bir anket uygulanmıştır.

Dönem sonunda deney ve kontrol grubunun ortak olarak girdikleri açık uçlu sorulardan oluşan final sınavı sontest olarak değerlendirilmiştir.

Çalışmanın pilot uygulamasında fizikokimya laboratuvarlarında tek bir sayfa olarak (A4) V-Diyagramlarının hazırlanmasının yetersiz kalabileceği gözlemlenmiştir. Bu durumla başedebilmek için bu çalışmada kavramsal kısım ve yöntemsel kısım için ilave çalışma yapraklarının kullanılması yoluna gidilmiştir. Diyagramın ilk bölümünü oluşturan kavramsal kısımda teori ve ilkeler ile kavramlar yer almaktadır. Ancak pilot çalışmada öğrencilerin kolaya kaçarak bu bölümde teori ve ilkeler ile kavramların sadece başlıklarını yazdıkları, konuyu kavramsal olarak detayland1rıp, irdelemedikleri görülmüştür. Bu durumun önüne geçebilmek için çalışmanın pilot uygulamadan sonraki asıl uygulamasında öğrencilerden kavramsal bölüme başlıklar halinde yazdıkları teori ve ilkeler ile kavramların açıklama ve tanımlarının yer aldığı ikinci bir çalışma kağıdı hazırlamaları istenmiştir. Fizikokimya laboratuvarlarında uygulanan deneyler uzun ve sonucunda elde edilen verilerin analiz edilmesi sonucu çizilen grafikler birden fazla ve büyük boyutlu olduğu için bu grafiklerin tek bir sayfada toplanmasının sıkışık ve karmaşık bir görüntüye sebep olarak diyagramın organizasyonunu bozacağı sonucu ortaya çıkmıştır. Bu sebeple diyagramın yöntemsel kısmı için de ilave bir çalışma yaprağı kullanılması uygun bulunmuştur.

28 kişilik deney grubundan birisi 4 diğerleri 3'er kişilik 9 deney grubu oluşturulmuştur. Gruplar öğrencilerin istekleri de dikkate alınarak rasgele oluşturulmuştur. Her bir grup farklı bir deney yapacak şekilde bir haftada 9 farklı deney (Bakınız Tablo 1) aynı anda yürütülmüştür. Deneyler her hafta dönüşümlü olarak yaptırılmıştır, böylece her grup dönem sonunda 9 deneyi tamamlamıştır. Gruplar bu yönden de birbirlerine yardımcı olmuşlardır. Böylece gruplararası etkileşim de desteklenmiştir. Yani o hafta deney yapan grup takıldıkları noktalarda bir önceki hafta 
aynı deneyi yapan gruptan destek alabilmiştir. Fakat nadir de olsa bu etkileşimin bazı deneylerde birbirinin kopyası V Diyagramlarının oluşması gibi bazı dezavantajlara neden olduğu gözlemlenmiştir.

Diyagramın ikinci kısmı olan yöntemsel kısımda kayıtlar ve veri dönüşümleri bölümlerinde yapılması gereken işlemler ve çizilmesi gereken grafikler tek bir sayfaya sığmayacağından öğrencilerden işlemleri ve grafikleri grafik kağıdında, elde edilen sonuç ve buna bağlı yorumları diyagram üzerinde göstermeleri istenmiştir. Sonuçta ortaya çıkan V Diyagramı deneyi kısa ve öz biçimde şematik olarak bize vermiştir. Öğrenci geriye dönüp baktığı zaman eline aldığı bir diyagram üzerinde araştırma basamaklarının hepsini aşama aşama, belli bir düzen içinde organize bir biçimde görebilmektedir.

Çalışmanın sonunda, öğrencilerin V Diyagramını ilk kez bu uygulama kapsamında öğrenip, kullanmalarına rağmen, V Diyagramının mantığını kavradıkları, hazırlarken fazla zorlanmadıkları görülmüştür.

\section{Verilerin Toplanması}

Yapılan çalışmalar boyunca grupların oluşturulması ve verilerin toplanmasında iki farklı ölçüm aracı kullanılmıştır. Bunlar;

1. Laboratuvar Testi: Laboratuvar testi 25 anket sorusundan oluşmaktadır. Testin orjinali Tümay (2001) tarafından hazırlanmıştır. Bu çalışmada kullanılabileceğine uzman görüşleri doğrultusunda testin kapsam geçerliliğinin bu çalışma için uygun olduğu sonucuna varılarak karar verilmiştir.

2. Final Soruları: Bu çalışmada sontest olarak her iki grupta da final soruları kullanılmıştır. Sorular fizikokimya laboratuvarı öğretim üyeleri tarafından beş adet ve açık uçlu olarak hazırlanmıştır.

\section{Verilerin Analizi}

Uygulama sonunda elde edilen nicel veriler betimsel istatistik teknikleri kullanılarak analiz edilmiştir. Nitel verilerin analizinde ise içerik analizi tekniği kullanılmıştır. Kalıpları, temaları, önyargıları ve anlamları tespit 
etmek amacıyla belirli bir materyalin dikkatlice, ayrıntılı ve sistematik olarak incelenmesi ve yorumlanmasına içerik analizi denilir (Berg ve Lune, 2015). Nitel bulgular nicel bulguları desteklemek amaciyla kullanılmış, öğrenci ifadelerinden doğrudan alıntılara yer verilmiştir.

\section{Bulgular}

\section{Laboratuvar Testi İle İlgili Bulgular}

Söz konusu anket 8 tanesi açık uçlu 17 tanesi çoktan seçmeli olmak üzere 25 sorudan oluşmaktadır. Ankette yer alan soruların ilk 12 tanesi öğrencilerin laboratuvar çalışmalarıyla ilgili görüşlerini, diğer 13 soru ise V-Diyagramıyla ilgili görüşlerini belirlemeye yönelik olarak hazırlandı. Anket sadece deney grubundaki 28 öğrenciye uygulandı.

Öğrencilerin anket sorularına verdikleri cevaplar incelendiğinde, öğrenciler, bugüne kadar hazırladıkları klasik deney raporlarından yeteri kadar yararlanamadıklarını, teorik bilgileri klasik deney raporunda kitaptan kopya ederek deney raporuna geçirdiklerini bu yüzden de teorik bilgiler ile laboratuvardaki gözlemleri arasında anlamlı ilişkiler kuramadıklarını ve zaman zaman deneyleri boş yere yaptıkları duygusuna kapıldıklarını ifade etmişlerdir.

Tablo 2. İlk ü̧̧ anket sorusu ve öğrencilerin bu sorulara verdikleri cevaplara ait frekans değerleri

\begin{tabular}{lccc}
\hline \multicolumn{1}{c}{ Sorular } & Hiç(f) & $\begin{array}{c}\text { Kıs- } \\
\text { men(f) }\end{array}$ & Çok(f) \\
\hline $\begin{array}{l}\text { 1. Genel kimya laboratuvarında bugüne dek hazır- } \\
\text { ladığınız deney raporları size ne derece de yararlı } \\
\text { oldu veya ne derece de yararını gördünüz? }\end{array}$ & 2 & 20 & 6 \\
\hline $\begin{array}{l}\text { 2. Gördüğ̈ünüz derslerle laboratuvarınızın bağlantı- } \\
\text { sinı ne derece iyi kurabiliyorsunuz? }\end{array}$ & 0 & 18 & 10 \\
\hline $\begin{array}{l}\text { 3. Deneyi yaptıktan sonra konuyu anlamanızda } \\
\text { veya pekiştirmenizde ne derece yararını görüyorsu- } \\
\text { nuz? }\end{array}$ & 3 & 11 & 14 \\
\hline
\end{tabular}

Tablo 2'de görüldüğü üzere klasik raporların kendilerine ne derece yararlı olduğunu anlamak için sorulan birinci soruya öğrencilerin sadece 
\%21,42'si (6 kişi) çok cevabını vermiştir. Gerekçe olarak ise raporları göstermelik hazırladıklarını, derslerin yoğunluğundan dolayı önem veremediklerini, kitapta ne yazıyorsa kopya ettiklerini ve öğretici bir yanı olmadığını düşündüklerini ifade etmişlerdir.

Teorik bilgiler ile laboratuvar gözlemleri arasında bağlantı kurup kuramadıklarını anlamak için sorulan ikinci soruya öğrencilerin hiçbiri olumsuz yanıt vermemiştir. Bu da az da olsa laboratuvarların amacına uygun bir sonuçtur. Ancak öğrencilerin \% 35,71'i (10 kişi) çok cevabını vermiştir. Gerekçe olarak ise ders ve laboratuvarların eş zamanlı olmamasını, bazı deneylerin içerdiği ilke, prensip ve teorilerinin derste öğrenilmeden deney yapıldığını dolayısıyla da teorik bilgi ile deneyler arasında bağlantı kuramadıklarını ifade etmişlerdir.

Deneylerin konuyu anlamaya veya pekiştirmeye katkısını öğrenmek amacıyla sorulan üçüncü soruya öğrencilerin \% 50'si (14 kişi) çok cevabını vermiş̧ir. Bu öğrencilerin laboratuvarın öneminin farkında olduklarını gösteren bir sonuç olarak düşünülebilir.

Tablo 3. Beşinci ve altıncı anket sorusu ve öğrencilerin bu sorulara verdikleri cevaplara ait frekans değerleri

\begin{tabular}{llll}
\hline Sorular & Hiç $(f)$ & $\operatorname{Kismen}(f)$ & Çok $(f)$ \\
\hline $\begin{array}{l}\text { 5. Bir deney raporu sizce deneyi ne derecede } \\
\text { iyi özetleyebilmektedir? }\end{array}$ & 2 & 18 & 8 \\
\hline $\begin{array}{l}\text { 6. Sizce deneylerin bilgiyi sadece teorik olarak } \\
\text { vermesi ne kadar yararlı olur? }\end{array}$ & 15 & 10 & 3 \\
\hline
\end{tabular}

Öğrencilerin laboratuvara olan olumsuz yaklaşımında klasik deney raporlarının bir payının olup olmadığını anlamak için sorulan beşinci soruya yukarıda Tablo 3'te sunulduğu üzere öğrencilerin sadece $\% 28,57$ 'si (8 kişi) çok cevabını vermiştir. Burada öğrenciler; raporları sadece hazırlamış olmak için hazırladıklarını yani bir zorunluluktan hazırladıklarını, ciddiye almadıklarını ya da rapor hazırlamayı gereksiz bulduklarını da ifade etmişlerdir.

Tablo $4^{\prime}$ te görüldüğü üzere öğrencilerin laboratuvar çalışmalarına bakış açılarını daha net anlayabilmek için sorulan dördüncü soruya öğrencilerin \%46,42'i evet cevabını vermiştir. Hayır cevabını veren öğrenciler laboratuvarların, öğrenilen bilgileri pratiğe dökmek için bir yol 
olduğunu, konuların mantığını anlayıp ezberden kurtulmak için önemli olduğunu ve laboratuvarda deney yapmaktan zevk aldıklarını dile getirmişlerdir.

Tablo 4. Dört, yedi, dokuz ve onikinci anket sorusu ve öğrencilerin bu sorulara verdikleri cevaplara ait frekans değerleri

\begin{tabular}{llc}
\hline Sorular & Evet $(f)$ & Hayır $(f)$ \\
\hline $\begin{array}{l}\text { 4. Laboratuvarda deneyleri boş yere yaptığınız hissine } \\
\text { kapıldınız mı? }\end{array}$ & 46.42 & 53.58 \\
\hline 7. Laboratuvara hazırlanıp geliyor musunuz? & 89,28 & 10.72 \\
\hline $\begin{array}{l}\text { 12. Laboratuvarların tam bir öğrenme ortamı sağladığını } \\
\text { düşünüyor musunuz? }\end{array}$ & 46.42 & 53.58 \\
\hline $\begin{array}{l}\text { 9. Deney yaparken kendinizi daha çok bir aşçı gibi mi yoksa } \\
\text { bir bilim adamı gibi mi hissediyorsunuz? }\end{array}$ & Aşçı $(f)$ & Bilim İnsanı $(f)$ \\
\cline { 2 - 3 } & 46,42 & 53.58 \\
\hline
\end{tabular}

Yedinci soruya öğrencilerin \%89,28'i evet cevabını vermişlerdir. Ama bu hazırlık çoğunlukla laboratuvar kitabında yer alan teorik kısmın okunmasıyla sınırlı kalmaktadır. Laboratuvar dersi başlamadan önce yapılan küçük sınav da öğrencilere bu ön hazırlığı zorunlu kılıyor. Onikinci soruya öğrencilerin \%46,42'si evet cevabını vermiştir.

“Deney yaparken kendinizi daha çok bir aşçı gibi mi yoksa bir bilim adamı gibi mi hissediyorsunuz?" şeklindeki dokuzuncu soruya öğrencilerin neredeyse yarısına yakını \%46,42 "aşçı"; \%53.58'i ise "bilim adamı" cevabını vermiştir.

"Sizce bir deney raporu hangi bölümleri mutlaka içermelidir?" şeklindeki sekizinci sorusuya öğrencilerin verdikleri cevaplar incelendiğinde Tablo 5'te görüleceği üzere, öğrencilerin klasik raporda yer alan bölümleri belirttikleri ortaya çıkmaktadır. Öğrencilerin bu soruya verdikleri cevaplar gruplandırılarak aşağıda Tablo 5 'te sunulmuştur.

Tablo 5. Öğrenci görü̈şlerine göre bir deney raporunun mutlaka içermesi gereken bölïmlere ait frekans ve yüzde değerleri (Not: 3 öğrenci soruya cevap vermemiştir. Bir öğrenci birden fazla cevap verebilmiştir.)

\begin{tabular}{lcc}
\hline Bölümler & Öğrenci Sayısı $(f)$ & Yüzde Değeri $(\%)$ \\
\hline Deneyin adı & 3 & 12 \\
\hline Deneyin amacı & 14 & 56 \\
\hline Teorik bilgi & 16 & 64 \\
\hline Deneyin yapılışı & 11 & 44 \\
\hline Araç-gereç & 7 & 28 \\
\hline Sonuç & 20 & 80 \\
\hline
\end{tabular}


Ankette yer alan diğer sorular öğrencilerin V-Diyagramıla ilgili görüşlerini belirlemek amacıyla hazırlanmış sorulardır.

"V-Diyagramı ve klasik deney raporu arasındaki farkın" sorulduğu onüçüncü soruya öğrencilerin verdikleri cevaplar incelendiğinde belirlenen bulgular Tablo 6'da maddeler halinde sunulmuştur.

Tablo 6. Öğrenci ifadelerine göre V-diyagramı ve klasik deney raporu arasındaki farklar

V Diyagramın hazırlarken kişi daha dikkatli oluyor.

V Diyagramı daha düzenli ve estetik.

Klasik deney raporu uzun ve yorucu, $V$ Diyagramı ise daha öz ve net bilgiler içeriyor.

$V$ Diyagramı önceden hazırlık istediği için deneye hazırlıklı gelmemizi sağladı. Klasik rapor ise sonradan yazllabiliyor.

$V$ Diyagramı daha disiplinli bir çalı̧ma gerektiriyor. Klasik raporda ise kitabın aynısını yazmak yeterli oluyor. İlave bir çaba sarf etmek gerekmiyor.

V Diyagramı için konunun hâkimiyeti gerekiyor. Klasik deney raporu için böyle bir şart yok.

Tablo 7'de görüldüğü üzere V-Diyagramının ön hazırlık gerektirmesi hakkındaki onbeşinci soruya öğrencilerin \%21,42'si (6 kişi) hayır cevabını vermiştir. \%78,57'si (22 kişi) ise evet veya kısmen cevabını vermiştir. Olumsuz cevap veren öğrenciler ise " daha önceden de hazırlıklı geldikleri" yorumunu yaptılar.

V-Diyagramı hazırlığının öğrencileri düşünmeye sevk edip etmediğiyle ilgili onaltıncı soruya öğrencilerin \%75'i (21 kişi) evet veya kısmen cevabını vermiştir.

V-Diyagramının teorik bilgi ve laboratuvar gözlemleri arasında bağlantı kurmalarını sağlayıp sağlamadığına yönelik olarak sorulan onyedinci soruya öğrencilerin \%53,57'si (15 kişi) evet cevabını vermiştir.

V-Diyagramlarının kavram bilgisine bir katkısının olup olmadığını anlamak amaciyla sorulan onsekizinci soruya öğrencilerin \%25'i (7 kişi) olumsuz cevap vermiştir. Öğrencilerin \%75'i (21 kişi) ise evet veya kısmen cevabını vermiştir. Bu cevabı verme gerekçelerini ise şu şekilde açıklamışlardır: "Kavramlar kısmı tüm kavramları daha iyi, açık ve net bir şekilde öğrenmemizi sağladı. Kavramları tanımama ve kavram tanımlarını öğrenmeme katkısı oldu. Ayrıca bazı kavramların tanımlarını yanlış ya da eksik bildiğimin farkına varmamı sağladı." 
Tablo 7. V-Diyagramıyla ilgili anket soruları ve öğrencilerin bu sorulara verdikleri cevaplara ait frekans değerleri

\begin{tabular}{lccc}
\hline Sorular & Evet $(f)$ & Kısmen $(f)$ & Hayır $(f)$ \\
\hline $\begin{array}{l}\text { 15. V Diyagramlarının ön hazırlık gerektirmesi } \\
\text { sizi araştırmaya sevk etti mi? }\end{array}$ & 13 & 9 & 6 \\
\hline $\begin{array}{l}\text { 16. V Diyagramı hazırlığı sizi düşünmeye sevk } \\
\text { etti mi? }\end{array}$ & 12 & 9 & 7 \\
\hline $\begin{array}{l}\text { 17. V Diyagramı laboratuvar gözlemleri ve teorik } \\
\text { bilgi arasında ilişki kurmanıza katkı sağladı mı? }\end{array}$ & 15 & 7 & 6 \\
\hline $\begin{array}{l}\text { 18. V Diyagramının kavramların öğrenilmesine } \\
\text { ya da kavram yanılgılarınızın tespitine katkısı } \\
\text { oldu mu? }\end{array}$ & 13 & 8 & 7 \\
\hline $\begin{array}{l}\text { 19. V Diyagramının deneyle ilgili soru sorma ye- } \\
\text { teneğinizi geliştirmenize katkısı oldu mu? }\end{array}$ & 11 & 10 & 7 \\
\hline $\begin{array}{l}\text { 20. V diyagramının grup çalışmasına katkısı oldu } \\
\text { mu? }\end{array}$ & 10 & 9 & 9 \\
\hline
\end{tabular}

"V-Diyagramının deneyle ilgili soru sorma yeteneğinize katkısı oldu mu?" şeklindeki ondokuzuncu soruya öğrencilerin \%75'i (21 kişi) evet veya kısmen cevabını vermiştir. Öğrencilerin böyle bir cevap verme gerekçeleri öğrenci ifadelerine dayalı olarak şöyle özetlenebilir: "Klasik raporları hazırlarken araştırma gereği duymazken V-Diyagramı bizi araştırmaya yöneltti ve ufkumuzu genişletti. Deneyin amacına yönelik sorular türetebilmemize katkı sağladı. Özellikle odak soru bulma noktasında ilk dönemlerde zorlandım. Ama artık daha kolay sorular bulabiliyorum."

"V-diyagramının grup çalışmasına katkısı oldu mu?" şeklindeki yirminci soruya öğrencilerin \%67.85'i (19 kişi) evet veya kısmen cevabını vermiştir.

"V-Diyagramının en çok hangi kısmının daha yararlı olduğunu düşünüyorsunuz? Neden?" şeklinde sorulan yirmiikinci soruya verilen cevaplar incelendiğinde öğrencilerin çoğunlukla "odak soru" cevabı verdikleri görülmüştür. Buna gerekçe olarak da deneyin amacının odak soruda gizli olduğu, odak soruyu sorabilmek için konuya hâkim olmak ve deneyin mantığını kapmış olmak gerektiği belirtmişlerdir. Öğrencilerin bu soruya verdikleri cevaplara ait frekans ve yüzde değerleri aşağıda Tablo 8'de sunulmuştur. 
Tablo 8. Öğrencilerin V-Diyagramının en yararlı buldukları kısımlarına ait frekans ve yüzde değerleri (Not: 2 öğrenci soruya cevap vermemiştir. Bir öğrenci birden fazla cevap verebilmiştir.)

\begin{tabular}{lll}
\hline V Diyagramının Bölümleri & $f$ & $\%$ \\
\hline Teori-ilkeler & 7 & 26,92 \\
\hline Kavramlar & 8 & 30,77 \\
\hline Odak soru & 15 & 57,69 \\
\hline Deneysel iddialar & 7 & 26,92 \\
\hline Bilgi iddiaları & 10 & 38.46 \\
\hline Veri Dönüşümleri & 9 & 34.62 \\
\hline
\end{tabular}

“Üniversiteye başladığınız ilk yıldan itibaren deney raporu hazırlama yöntemi olarak V-Diyagramlarını kullanmış olmayı ister miydiniz? Neden?" şeklinde sorulan yirmidördüncü soruya öğrencilerin \% 62,96'sı evet cevabını vermiştir. Evet cevabı veren öğrencilerden biri cevabının nedenini: "V-Diyagramının klasik rapordan daha yararlı olduğunu düşünüyorum, o yüzden isterdim. Ama biz bu en yoğun yılımızda karşılaştığımız için çok iyi değerlendiremedik diye düşünüyorum." şeklinde açılamıştır. Yine bir başka öğrenci cevabının nedenini "Hazırlarken çok vakit harcıyorum. Ama çalışırken çok yararın gördüm. Ayrıca klasik rapora göre çok daha faydall, deney hakkında daha fazla bilgi veriyor. Yani daha verimli ve düzenli bir yöntem. Deneyin tümünü tek sayfada görme imkanı sağladığı için bilgiler daha kahıcı oldu. Üniversiteye başladığımız ilk yıldan itibaren V diyagramlarını kullansaydık çok daha faydalı olurdu" şeklinde açıklamıştır.

Ankette "V-diyagramlarının öğrenmenize olumlu katkı sağladığını düşünüyor musunuz? Neden?" şeklinde sorulan yirmibeşinci soruya öğrencilerin \%65,38'i olumlu cevap vermiştir. Öğrenciler klasik rapor hazırladıkları dönemde bir deney için pek çok farklı rapor ortaya çıktığını ve raporlar arasında belli bir standart sağlanmadığını, V-diyagramı sayesinde raporlarda bir düzenin ve standartın yakalandığını söylemişlerdir. Odak soru sayesinde konunun önemli noktasının yakalandığını, bilimsel iddialar kısmının ise deneyde elde edilen sonuçların yorumlanmasında farklı bir bakış açısı getirdiğini, kısacası tüm kısımlarıyla V-diyagramının konuya tamamen hâkim olmalarında büyük katkı sağladığını dile getiren öğrenciler doğru hazırlanan bir V-diyagramının öğrenmeye olumlu katkı sağlayacağı yorumunu yapmışlardır. 
Deney ve kontrol grubundaki tüm öğrencilerin dönem sonunda girdikleri final sınavındaki açık uçlu sorulara (sontest) verdikleri cevaplar betimsel istatistik teknikleri ile analiz edilmiştir. Analiz sonuçları aşağıda Tablo 9'da sunulmuştur.

Tablo 9. Öğrencilerin sonteste verdikleri cevaplara ait frekans ve yüzde değerleri

\begin{tabular}{lccc}
\hline & \multicolumn{3}{c}{ Sontest (f- \%) } \\
\cline { 2 - 4 } Gruplar & Doğru cevap & Yanlış Cevap & Toplam \\
\hline Kontrol Grubu & $18-64.29$ & $10-35.71$ & $28-100$ \\
\hline Deney Grubu & $24-85.71$ & $4-14.29$ & $28-100$ \\
\hline
\end{tabular}

Deney grubunda yer alan öğrencilerden 24 'ü final sorularını doğru cevaplarken; kontrol grubundaki öğrencilerin 18'i final sorularını doğru cevaplamıştır. Bu sonuçlar V-Diyagramlarının öğrencilerin fizikokimya laboratuvar deneylerini öğrenmelerine belli bir oranda olumlu etki ettiğinin bir göstergesidir. V-Diyagramının fizikokimya laboratuvar deneylerini öğrenme başarısını arttırdığını söyleyebiliriz.

\section{Tartışma}

V-diyagramının fizikokimya laboratuvarlarında deney raporlarının hazırlanmasında kullanılmasının kimya öğretmeni adaylarının öğrenmesine olan etkilerinin incelendiği bu çalışmada, deney grubunda bulunan ve Vdiyagramı kullanarak rapor hazırlayan öğrencilerin kontrol grubundaki öğrencilere göre final sınavında (sontest) daha başarılı oldukları tespit edilmiştir. Bu bulgu alanyazındaki bazı çalışmaların bulgularıyla uyumludur. Ayvacı ve İpek Akbulut (2012); V-diyagramının öğrencilerin psikomotor becerilerini geliştirdiğini, bilişsel alanda kavramsal öğrenmeye katkı sağladığını ve öğrencilerin alma, karşılık verme gibi alt düzeyde de olsa bazı duyuşsal özelliklerini etkilediğini tespit etmişlerdir.

Yavuz ve Kıyıcı (2014) fen ve teknoloji laboratuvar uygulamaları dersinde, laboratuvarda eğitim öğretim faaliyetleri içerisinde $V$-diyagramı ve kavram haritası kullanımının öğrencilerin başarı ve eleştirel düşünme eğilimlerini olumlu yönde etkilediğini tespit etmişlerdir.

Alanyazında çalışmamızın bulgularıyla örtüşmeyen bulgular da sözkonusudur. Mesela Lehman ve diğerleri (1985), siyah Amerikalıların öğ- 
renim gördüğü bir lisede, biyoloji kavramlarının anlamlı bir şekilde öğrenilmesinde, kavram haritası ve V-diyagramı araçlarının kullanımının ne düzeyde etkili olduğunu incelemişlerdir. Çalışmaları sonucunda deney ve kontrol grupları arasında anlamlı bir fark tespit etmemiştir. Bu sonucu deney grubu öğretmenleri ve öğrencilerinin bu yöntemlere yeterince aşina olmamaları ve uygulama süresinin yetersizliği ile ilişkilendirerek açıklamiştır.

Bu çalışmada "Laboratuvarda deneyleri boş yere yaptığınız hissine kapıldınız mı?" ve Laboratuvarların tam bir öğrenme ortamı sağladığını düşünüyor musunuz?" sorularına öğrencilerin neredeyse yarısına yakınının evet cevabını vermesi manidardır. Ayrıca "Deney yaparken kendinizi daha çok bir aşçı gibi mi yoksa bir bilim adamı gibi mi hissediyorsunuz?" sorusuna öğrencilerin neredeyse yarısına yakını $(\% 46,42)$ aşçı cevabını vermiştir. Öğrenciler, deney yapılışlarının kitapta "yemek tarifi gibi" olduğunu bunun yerine deneyde hangi maddenin ne amaçla kullanıldığını açıklayan şekilde olmasının daha doğru olacağını belirtmişlerdir. Öğrencilerle yapılan bire bir görüşmelerde de öğrenciler: "Bazı deneylerde laboratuvarda yaptı̆̆ımız çalışmalarla teori arasında bir ilişki kuramıyoruz. Bu yüzden de deneyleri boşa yapıyormuş hissine kapılıyoruz. İşte o zaman deney yapmak, yemek yapmaktan farksız hale geliyor" şeklinde serzenişlerde bulunmuşlardır. Bu bulgular bize öğrencilerin yaklaşık yarısının deneyleri boş yere yaptığı duygusuna kapıldığını gösterir ki bu da laboratuvarların tam bir öğrenme ortamı sağlama noktasında eksikleri olduğunun bir kanıtı olarak yorumlanabilir. Alanyazında da laboratuvar çalışmalarının etkinliği konusunda bazı yetersizliklerin olduğunu gösteren çalışmalar vardır.

Nakiboğlu ve Meriç (2000) laboratuvar çalışmalarının amacına ulaşmasının, derslerdeki teorik bilgiler ile deneyler arasında anlamlı ilişkiler kurulmasına ve laboratuvarın aynı zamanda bir öğrenme ortamı haline getirilmesine bağlı olduğunu vurgulamaktadır. Geleneksel laboratuvar çalışmaları, öğrencilerin deneyleri planlama, gözlem yapma, ölçme ve sonuç çıkarma gibi bilimsel süreç becerilerini geliştirmede yeterince etkili olmamaktadır (Kyle, Penick ve Shymansky, 1979; Tamir, 1977).

Çalışmamızda kullandığımız anketin laboratuvar ve klasik rapora yönelik olarak hazırlanan sorularına öğrencilerin verdikleri cevaplarının incelenmesi sonucu belirlenen ve bulgular bölümünde detaylı bir biçimde 
sunulan sorunların, öğrencilerin laboratuvarlarda doğru yönlendiril-memelerinden kaynaklandığı yorumu yapılabilir. Tüm bu sorulara verilen cevaplar öğrencilerin laboratuvar çalışmalarında yaşadıkları sorunların farkında olmalarına rağmen ne yapılması gerektiği noktasında pek fazla fikir sahibi olmadıklarını göstermektedir. Çünkü öğrencilerin "Sizce bir deney raporu hangi bölümleri mutlaka içermelidir?" sorusuna verdikleri cevaplar incelendiğinde (Bakınız Tablo 5), öğrencilerin laboratuvar çalışmalarında kullanmaya alışık oldukları klasik raporda yer alan bölümleri (Deneyin adı, Deneyin amacı, Teorik bilgi, Deneyin yapılışı, Araç-gereç, Sonuç) vurguladıkları ortaya çıkmıştır.

Öğrencilerden V- diyagramıyla klasik deney raporunu karşılaştırmalarını istediğimizde öğrencilerin tamamen $V$-diyagramı lehine görüş bildirdikleri (Bakınız Tablo 6) görülmüştür. Öğrencilerin V-diyagramıyla ilgili görüşlerini belirlemeye yönelik sorulara verdikleri cevaplarda büyük çoğunluğun V-diyagramlarının ön hazırlık gerektirdiğini ve V-diyagramı hazırlarken bazı konularda daha ayrıntılı kaynaklara başvurmak durumunda kaldıklarını ve özellikle kavramları araştırmaya yönelttiğini ifade ettiler. Öğrencilerin yarısı V-diyagramının teorik bilgi ve laboratuvar gözlemleri arasında bağlantı kurmalarını sağladığın; dörtte üçü V- diyagramlarının kavram bilgisine katkı sağladığını belirtmiştir. Gowin ve Novak'a (1984) göre V- diyagramı öğrencilerin teorik bilgi ile laboratuvar çalışmaları arasında ilişki kurmalarını sağlayarak, laboratuvar raporlarının daha anlaşılabilir ve yararlı hale getirilmesine imkân tanır. Öğrencilerden biri V- diyagramının kavram bilgisine olan katkısını "Kavramlar kısmı tüm kavramları daha iyi, açık ve net bir şekilde öğrenmemizi sağladı. Kavramları tanımama ve tanımların öğrenmeme katkısı oldu. Ayrıca bazı kavramların tanımlarını yanlış ya da eksik bildiğimin farkına varmamı sağladı..." şeklinde izah etmiştir.

Öğrencilerin yine dörtte üçü V- diyagramının deneyle ilgili soru sorma yeteneğine katkısı olduğunu belirtmiştir. Yapılan görüşmede bu soruyla ilgili olumlu görüş bildiren öğrencilerin biri cevabını "Klasik raporları hazırlarken araştırma gereği duymazken $V$ - diyagramı bizi araştırmaya yöneltti ve ufkumuzu genişletti. Deneyin amacına yönelik sorular türetebilmemize katkı sağladı. Özellikle odak soru bulma noktasında ilk dönemlerde zorlandım. Ama artık daha kolay sorular bulabiliyorum" şeklinde detaylandırmıştır. Ayrıca öğren- 
cilerin büyük çoğunluğu V- diyagramının odak soru kısmının en çok yararlı olduğunu düşünmektedirler. Bu düşüncelerini ise deneyin amacının odak soruda gizli olduğunu, odak soruyu sorabilmek için konuya hâkim olmak ve deneyin mantı̆̆ını kapmış olmak gerektiğini belirterek açıklamişlardır.

Alanyazında V- diyagramlarıyla ilgili yukarıda ortaya koyduğumuz öğrenci görüsslerini destekleyen tespit ve vurgular sözkonusudur. V- diyagramları laboratuvar çalışmalarının gerçekleştirilmesi sırasında teorik bilgi ile ilişki kurarak temel kavramların doğru anlaşılmasının sağlanması yanında, öğrenci başarısının iyi bir şekilde ölçülmesi ve değerlendirilmesine de imkân sağlar. Ayrıca, öğrenciye laboratuvar öncesi hazırlık yapma fırsatı verir (Nakiboğlu ve Meriç, 2000). V-diyagramı sayesinde eski bilgilerle, yeni yorumlar yapılarak bilgi yapılandırılırken, tüm elemanların birbirleriyle olan aktif etkileşimi organize bir biçimde şematize edilir. V- diyagramlarına eğitim-öğretim faaliyetlerinde yer verildiğinde, öğrenciler bilgi ve bilginin oluşum sürecinden haberdar olurlarken aynı zamanda kavramlar arasındaki ilişkileri de anlamlandırırlar ve elde edilen yeni bilgilerle kavramlarını yeniden yapılandırabilirler (Novak, 1998; Novak, Gowin ve Johansen, 1983). Çünkü V- diyagramı gözlem yaptığımız olay, olgu veya kavram üzerinde ne gördügümüz ve nasıl yorumladığımız arasındaki ilişkiyi ortaya çıkaran yollardan biridir (Gürdal, Şahin ve Çağlar, 2001). V- diyagramı ile öğrenciler yaptıkları ve katıldıkları laboratuvar aktivitesinden sonra gözlemledikleri olaylarla daha önce bildikleri arasındaki ilişkileri aynı anda görebilirler. Böylece bilgiler daha şematik ve organize bir şekilde kaydedileceği için öğrenme de daha organize, anlamlı ve kalıcı olacaktır (Atılboz ve Yakışan, 2003).

\section{Öneriler}

Bu çalışmada elde edilen bulgulara dayalı olarak laboratuvar çalışmalarını daha verimli ve anlamlı kılmak amacıyla, geleneksel öğretim yaklaşımlarının esas alındığı laboratuvar uygulamalarının dışına çıkılarak öğrencinin öğrenmede daha çok sorumluluk aldığ1 ve aktif olduğu çağdaş öğretim yaklaşımlarının esas alındığı laboratuvar uygulamaları kullanılmalıdır. Bu çalışmada anketin V- diyagramlarıyla ilgili bölümününden elde edilen bulgular, V- diyagramlarının; öğrencilere deneyle ilgili sorular 
sordurması, ön hazırlık gerektirmesi, teori ile deneyi ilişkilendirmesi, teoride geçen kavramların öğrenilmesini ve sonuçların yorumlanmasını sağlaması gibi avantajlarının olduğunu ortaya koymuştur. Bu avantajlarıyla V- diyagramlarının laboratuvar çalışmalarını daha etkin ve anlamlı kılma ve öğrencilerin öğrenmelerine katkıda bulunma potansiyeline sahip olduğunu söyleyebiliriz.

Bu nedenle özellikle öğrencilerin araştırma, problem çözme, gözlem yapma ve bunlar arasında ilişkiler kurma gibi becerileri kazanmalarında önemli bir role sahip olan laboratuvar derslerini gerçek bir öğrenme ortamı olarak kullanabilmek ve geleneksel doğrulama yönteminin ezberci yaklaşımından kurtarabilmek için V-diyagramları gibi materyallerden yararlanılması gerekmektedir. Çalışmamızda sadece deney raporlarının hazırlanmasında kullanılan V- diyagramları kimya derslerinde, kavramsal bilgi ve deneysel çalışmalar arasında ilişki kurmada ve kavram öğreniminde öğrencilere yardımcı olmakta, bu anlamda öğretmene de öğretim için avantaj sunmaktadır. V-diyagramlarının hemen her düzeydeki bütün deneylerde rahatça kullanılabilirliği, hazırlanma kolaylığı, laboratuvar öncesi öğrencileri araştırmaya sevk etmesi, kavram öğretimine yardımcı olması ve laboratuvar çalışmalarının tüm aşamalarını organize bir biçimde içermesi gibi önemli avantajları nedeniyle kimya öğretmeni adaylarını eğiten kimya eğitimcileri tarafından laboratuvar çalışmalarında kullanılması ve kullanımının yaygınlaştırılması kimya öğretmeni adaylarına daha nitelikli bir kimya eğitimi imkânı sunacaktır. Bu gibi materyallerle hizmet öncesi süreçte tanışan ve bu materyallere kimya öğretiminde nasıl yer vereceğini öğrenen kimya öğretmeni adaylarının öğretmen olduklarında bu materyalleri öğretimlerinde kullanma ihtimalleri daha yüksek olacaktır. 
EXTENDED ABSTRACT

\title{
Effect of The V-Diagram on The Prospective Chemistry Teachers' Learning of Physical Chemistry Laboratory Experiments and Their Ideas About V-Diagram
}

\author{
Emine Güler Akdemci - Derya Karataş - Ayşegül Derman
}

Necmettin Erbakan University, Ministry of National Education, Necmettin Erbakan University

The most important feature that distinguishes science from other sciences is that it allows students to develop scientific process skills primarily by giving importance to experimentation, observation, and exploration. (Adadan, 2015; Nakipoğlu, 2015). In today's world where science and technology are developing at a dizzying pace, science education is carried out with many different techniques and methods. One of the most effective methods among these methods is the laboratory method (Lawson, 1995). In the basic sciences, supporting theoretical subjects with experiments is very important for understanding the subjects. The role of laboratories in science education has an important role as a focal point (Adadan, 2015), therefore, the role of laboratories in science teaching has attracted the attention of many researchers (Adadan, 2015; Hodson, 1990; Hoffstein and Lunetta, 1982; Tamir, 1977).

The V-diagram is a V-shaped diagram developed by Gowin and Novak (1984) during the 70's in order to better understand and construct knowledge and is also called Vee heuristics, Vee map and V-diagram.

This diagram allows students to establish a relationship between theoretical knowledge and laboratory studies, making it possible to make laboratory reports more understandable and useful (Gowin and Novak, 1984; Novak, 1998).

The greatest benefit of using V-diagram in laboratory studies is to eliminate the discrepancies between the course and laboratory work by enabling students to establish a relationship between their theoretical knowledge and their observations in the laboratory. While most of the 
time the students are interested in the record and results of the experiments in their experiments, they cannot reach the information they want to give to the student. Using the V-diagram, the students form the data transformations based on the records they have obtained and reach the experimental and informational interpretations that the experiment wants to gain (Nakiboğlu, Benlikaya \& Karakoç, 2001; 2002). In this study, we aimed to increase the quality of physicochemistry laboratory applications by using V-diagrams, which enable the student to construct meaningful, permanent and organized information in his mind in the preparation of reports of physicochemistry experiments carried out with the traditional approach.

In current study, the effects of using V-diagram in the preparation of experimental reports in Physical Chemistry laboratories on the learning of prospective chemistry teachers were focused.

In the present study, the effect on the learning of the preparation of the reports of the 3rd grade prospective chemistry teachers using the V-diagram of Physicochemistry Laboratory I course experiments to the experiments of the Physicschemistry Laboratory I course was investigated. In the present study, a static group comparison pattern was used (Creswell, 2016, p. 172). Two different measurement tools, Laboratory Test and openended final exam questions were used to collect the data. 56 students who took Physical Chemistry Laboratory I course were randomly assigned into two groups as experimental group and control group. While the students in the experimental group prepared the experiment reports using the $\mathrm{V}$ diagram, the students in the control group prepared the experiment reports in the usual, conventional way. The obtained quantitative data were analyzed with descriptive statistical techniques and the success of the two groups was compared. Content analysis technique was used in the analysis of qualitative data. In the present study, it was found out that the effects of the use of the V-diagram in the preparation of the experiment reports in the physicochemistry laboratories on the learning of the prospective chemistry teachers were more successful in the final exam (posttest) than the students in the control group who prepared the report using the $\mathrm{V}$-diagram. This finding is consistent with the findings of some studies in the literature. Ayvacı and İpek Akbulut (2012) revealed that the V-diagram improves students' psychomotor skills, contributes to conceptual 
learning in the cognitive field, and affects some of the affective characteristics of students, such as receiving and responding. Yavuz and Kiyıc1 (2014) stated that the use of V-diagram and concept map in the teaching and learning activities in the laboratory in the science and technology laboratory applications course positively affected students' achievement and critical thinking dispositions. Based on the findings obtained in the present study, in order to make the laboratory studies more efficient and meaningful, laboratory practices based on contemporary teaching approaches in which the student takes more responsibility and active in learning should be used by going beyond the laboratory practices based on traditional teaching approaches. In the present study, the findings obtained from the part of the questionnaire related to V-diagrams; It has revealed that students have the advantages such as asking questions about the experiment, requiring preliminary preparation, associating the theory with the experiment, learning the concepts in the theory and providing the interpretation of the results. With these advantages, we may conclude that V-diagrams have the potential to make laboratory studies more effective and meaningful and contribute to students' learning.

Therefore, it is necessary to utilize materials such as V-diagrams in order to be able to use laboratory courses as a real learning environment and save the traditional validation method from the rote approach, especially for students to gain skills such as research, problem solving, observation and establishing relationships between them. In our study, only the V-diagrams used in the preparation of experimental reports help students to establish relationships between conceptual knowledge and experimental studies in chemistry courses and concept learning, and in this sense offer an advantage to the teacher for teaching. V-diagrams can be easily used in all experiments at almost all levels, ease of preparation, encouraging prelaboratory students to research, assisting concept teaching and organizing all stages of laboratory studies. and expanding its use will provide prospective chemistry teachers a more qualified chemistry education. The prospective chemistry teachers who meet such materials in the pre-service period and learn how to entegrate them in chemistry teaching are more likely to use these materials in their teaching. 


\section{Kaynakça / References}

Adadan, E. (2015). Kimya öğretiminde yönlendirilmiş araştırmaya dayalı laboratuvar uygulamaları. A. Ayas ve M. Sözbilir (Editörler), Kimya Öğretimi içinde (ss.27-56). Ankara: PEGEM.

Atılboz, N.G. ve Yakışan, M. (2003). V diyagramının genel biyoloji laboratuarı konularını öğrenme başarısı üzerine etkisi: Canlı dokularda enzimler ve enzim aktivitesini etkileyen faktörler. Hacettepe Üniversitesi Ĕ̆itim Fakültesi Dergisi, 25, 8-13.

Ayvacı, H.Ş. ve İpek Akbulut, H. (2012). Elektrik akımı ile ilgili kavramların gelişiminde V-diyagramlarının etkisini belirlemeye yönelik bir pilot çalışma. Erzincan Üniversitesi Eğitim Fakültesi Dergisi, 14(1), 109-126.

Berg, B. L., ve Lune, H. (2015). Sosyal bilimlerde nitel araştırma yöntemleri. Konya: Eğitim Yayınevi.

Creswell, J. W. (2016). Research design: Qualitative, quantitative, and mixed methods approaches. (S.B. Demir, Çev. Ed.), Ankara: Eğiten Kitap Yayınları

Çelikler, D., Güneş, M.H., Güneş, T. ve Şendil, K. (2008). V diyagramı uygulamalarının temel kimya laboratuvarı dersinde öğrenci başarısına etkisi. Ahi Evran Üniversitesi Kırşehir Eğitim Fakültesi Dergisi, 9(2), 5158.

Esiobu, G.O. ve Sayibo, K. (1995). Effect of consept and Vee mapping under three learning modes on students cognivite achievementin ecolgy and genetics. Journal of Research in Science Teaching, 32(9), 971-995.

Geban, Ö., Aşkar, P. ve Özkan, İ. (1992). Effects of computer simulated experiments and problem solving approaches on high school students. Journal of Educational Research, 86, 5-10.

Gürdal, A., Şahin, F. ve Çağlar, A. (2001). Fen eğitimi ilkeler, stratejiler ve yöntemler. İstanbul: Marmara Üniversitesi Yayınları.

Gowin, D.B. ve Novak, V.D. (1984). Learn how to learn. New York: Cambrige University Press.

Gurley-Dilger, L. (1992). Gowin's Vee. The Science Teacher, 50-57.

Hodson, D. (1990). A critical look at practical work in school science. School Science Review, 70(256), 33-40.

Hoffstein, A. ve Lunetta, V.N. (1982). The role of the laboratory in science teaching: Reglected aspects of research. Review of Educational Research 52(2), 201-217. 
Kyle, W. Jr., Penick, J. ve Shymanshy, J. (1979). Assessment and analyzing performance of students in collage laboratories. Journal of Research In Science Teaching, 16, 545-552.

Lawson, A.E. (1995). Science teaching and the development of thinking. California: Wadsworth Press.

Lehman, V.D., Carter, C. ve Kahle, J.B. (1985). Concept mapping, vee mapping and achievement: Results of a field study with black high school students. Journal of Research in Science Teaching, 22(7), 663-673.

MEB. (2018). Ortaöğretim kimya dersi öğretim programı. Ankara: Talim ve Terbiye Kurulu Başkanlığı.

Nakhlen, M.B. (1994). Chemical education research in the laboratory environment. Journal of Chemical Education, 71(3), 201-205.

Nakipoğlu, C. (2015). Kimya öğretiminde bilimsel süreç becerileri. A. Ayas ve M. Sözbilir (Editörler), Kimya Öğretimi içinde (ss.93-114). Ankara: PEGEM.

Nakiboğlu C., Benlikaya, R. ve Karakoç, Ö. (2001). Ortaöğretim kimya derslerinde V-diagramı uygulamaları. Hacettepe Üniv. Eğitim Fak. Dergisi. 21, 97-104.

Nakiboğlu C., Benlikaya, R. ve Karakoç, Ö. (2002). Fizikokimya laboratuvarlarında V-diagramı uygulamaları. V. Ege Fizikokimya Günleri.

Nakiboğlu, C., Benlikaya, R. ve Kalın, Ş.(2002). Kimya öğretmen adaylarında kimyasal kinetik ile ilgili yanlş̧ kavramlarm belirlenmesinde $V$ diyagramlarımın kullanılması. V. Ulusal Fen Bilimleri ve Matematik Eğitim Kongresi. 16-18/10/2002, Ankara.

Nakiboğlu, C. ve Meriç, G. (2000). Genel kimya laboratuvarlarında v diyagramı kullanımı ve uygulamaları. Balıkesir Üniversitesi Fen Bilimleri Enstitüsü Dergisi, 1(2), 58-75.

Novak, J. D. (1998). Metacognitive strategies to help students learning how to learn. Research Matters-to the Science Teacher. No.9802.

Novak, J.D., Gowin D.B. ve Johansen, G.T. (1983). The use of concept mapping and knowledge vee mapping with junior high school science students. Science Education, 67(5), 625-645.

Passmore, G.G. (1998). Using Vee diagrams to facilitate meaningful learning and misconception. Radiologic Science and Education, 4(1), 11-28.

Roehrig, G., Luft, V.A. ve Edwards, M. (2001). Versatile Vee maps. The Science Teacher, January, 28-31. 
Roth, W. (1990). Map Your way to a beter laboratory. The Science Teacher, April, 31-34.

Sarıkaya, Y. (1993). Fizikokimya. Ankara: Gazi Büro Kitabevi.

Sarıkaya, A. (2003). IX. Sinıf fizik dersine ait deneylerin öğretmen görüşlerine göre değerlendirilmesi ve seçilmiş deneyler için çalışma yapraklarıla $V$ diyagramlarının hazırlanması. Yüksek lisans Tezi, Ankara: YÖK Dökümantasyon Merkezi.

Serin, G. (2002). Fen eğitiminde laboratuvar. Fen Bilimleri Ĕ̆itimi Sempozyumu, Maltepe Üniversitesi, 403-406.

Sülün, Y., Evren, A. ve Sülün, A . (2009). The effect of the usage of V-diagrams on the students success in biology laboratory. Erzincan Üniversitesi Eğitim Fakültesi Dergisi, 11(2), 84-98. Retrieved from http://dergipark.gov.tr/erziefd/issue/6001/80021

Tamir, P., (1977). How are the laboratories used? Journal of Research in Science Teaching, 14(4), 311-316.

Tobin, K E. G., Capie, W. (1982). Relationships between formal reasoning ability, locus of control, academic engagement and integrated process skill achievement. Journal of Research in Science Teaching, 19(2), 113-121.

Tümay, H. (2001). Üniversite kimya laboratuarlarında öğrencilerin kavramsal değişimi, başarısı, tutumu ve algılamaları üzerine yapılandırıcı öğretim yönteminin etkileri. Yayımlanmamış Yüksek Lisans Tezi, Ankara: Gazi Üniversitesi Eğitim Bilimleri Enstitüsü.

Yavuz, M. ve Balkan Kıyıc1, F. (2014). Laboratuarda V -diyagramı ve kavram haritası kullanımının başarı ve eleştirel düşünme eğilimine etkisi. Amasya Üniversitesi Eğitim Fakültesi Dergisi, 3(1), 150-174. doi:http://dx.doi.org/10.17539/aej.57690.

\section{Kaynakça Bilgisi / Citation Information}

Akdemci, E. G., Karataş, D. ve Derman, A. (2019). Kimya öğretmeni adaylarının fizikokimya laboratuvar deneylerini öğrenmelerine V-diyagramının etkisi ve V-diyagramı ile ilgili görüşleri. OPUSUluslararası Toplum Araştırmaları Dergisi, 13(19), 174-200. DOI: 10.26466/opus.538372 